- regimes have in place fair and clear procedures for granting humanitarian exemptions".

Iran has a strong domestic drug and vaccine industry, producing $90 \%$ of its own medicines, but these are mostly generic drugs. The country has to import newer and more sophisticated drugs such as for cancer treatments, and imports of these specialist medicines have been hardest hit by sanctions, says Richard Garfield of Columbia University in New York, who studies the effects of conflicts and economic sanctions on public health. Iran's industry is also highly dependent on imports of raw materials, with difficult-to-source ingredients for morecomplex drugs being most affected, he says.

According to Gorji, there are severe shortages of many drugs, including antibiotics, clofarabine for treating children with leukaemia and deferasirox for thalassaemia, a blood disorder common in Iran. He says that he witnessed the death of several children and adults as a result of drug shortages on a visit to Iran in early November. The routine child vaccine that protects against the bacterium Haemophilus influenzae, which causes severe pneumonia and meningitis in infants, is another casualty, adds Gorji. Also affected are parts and consumables for advanced medical technologies such as magnetic resonance imaging.

A major problem is the legal complexity of the sanctions - a maze of bans on certain transactions, individuals and organizations. Uncertainty as to what is and is not covered has led

many of the US, European and other companies that previously sold medical supplies to Iran to become reluctant to do so, says Garfield. Several companies, including Swiss financial firm Credit Suisse and London-based bank Standard Chartered, have incurred fines of hundreds of millions of dollars for falling foul of US sanctions against Iran, adding to the disincentive. Many firms are also nervous about being seen to be trading with an international pariah, Garfield adds.

Even when hospitals and research centres can find a supplier, tough sanctions on Iranian banks and foreign

\section{Many firms are also nervous about being seen to be trading with an international pariah.}

banks' dealings with Iran mean that they often cannot find a route to pay for medical supplies, says Seyed Hesamedin Madani, head of medical procurement for the Red Crescent Society of Iran in Tehran.

To make matters worse, sanctions affecting exports of Iranian oil have cut off the country's main supply of hard currency, says Madani, and the value of Iran's currency, the rial, has fallen by half against the dollar in the past 14 months, drastically increasing the price of medicines.

But the situation may be improving. In response to concerns from suppliers and banks about the difficulties in enacting exemptions for medical supplies, the US Department of the Treasury's Office of Foreign Assets Control (OFAC) issued new guidance in July. The guidelines aim to reassure US and non-US medical suppliers and banks that exporting medicines and medical devices is 'broadly authorized', provided that it does not involve Iranian organizations proscribed under sanctions.

The guidance also expanded the list of medical supplies that can be exported without OFAC approval. Garfield says that OFAC's action is a step in the right direction, but thinks that without more proactive measures, the weight of disincentives for firms to engage with Iran means that little is likely to change.

Last month's interim agreement between Iran and the group of countries known as the P5+1 - the United States, the United Kingdom, France, Russia and China, plus Germany, and facilitated by the European Union - has also raised hopes. It puts Iran's nuclear programme on hold for six months, thus stalling any development of a nuclear weapon, and will see sanctions eased slightly in return.

The deal also includes a proactive provision to establish a financial channel to facilitate humanitarian trade with Iran. This would involve designating foreign and Iranian banks that are authorized for this purpose, and in principle would provide an official route for suppliers and Iranian hospitals and medical centres to carry out transactions. Garfield welcomes the channel as long overdue, but he warns that making it work is another matter.

\title{
Hominin DNA baffles experts
}

\section{Analysis of oldest sequence from a human ancestor suggests link to mystery population.}

\section{BY EWEN CALLAWAY}

A nother ancient genome, another mystery. DNA gleaned from a 400,000-year-old femur from Spain has revealed an unexpected link between Europe's hominin inhabitants of the time and a cryptic population, the Denisovans, who are known to have lived much more recently in southwestern Siberia.

The DNA, which represents the oldest hominin sequence yet published, has left researchers baffled because most of them believed that the bones would be more closely linked to Neanderthals than to Denisovans. "That's not what I would have expected; that's not what anyone would have expected," says Chris Stringer, a palaeoanthropologist at London's Natural History Museum who was not involved in sequencing the femur DNA.

The fossil was excavated in the 1990s from

\section{FAMILY MYSTERY}

The mitochondrial genome of a 400,000-year-old femur has an unexpected link with a group of hominins called Denisovans. One interpretation is that this could be the result of interbreeding between more ancient populations, such as Homo antecessor and Homo heidelbergensis.

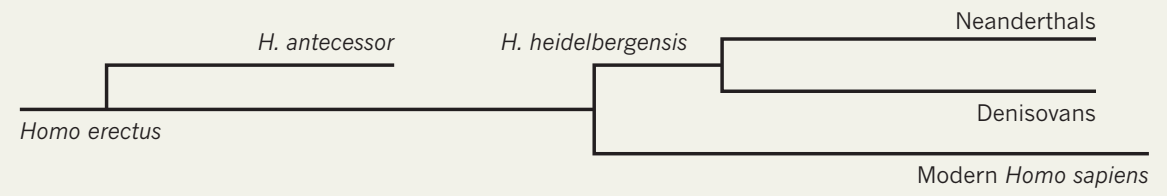

Femur from Sima de los Huesos hominin

1 million years ago 400,000 years ago

a deep cave in a well-studied site in northern Spain called Sima de los Huesos ('pit of bones'). This femur and the remains of more than two dozen other hominins found at the site have previously been attributed either to early forms of Neanderthals, who lived in Europe until about 30,000 years ago, or to Homo heidelbergensis, a loosely defined hominin population that gave rise to Neanderthals in Europe and possibly humans in Africa.

But a closer link to Neanderthals than to Denisovans was not what was discovered by the team led by Svante Pääbo, a molecular geneticist at the Max Planck Institute for Evolutionary 
$\sum_{\Sigma}^{\infty}$ Anthropology in Leipzig, Germany.

The team sequenced most of the femur's mitochondrial genome, which is made up of DNA from the cell's energy-producing structures and passed down the maternal line. The resulting phylogenetic analysis - which shows branches in evolutionary history placed the DNA closer to that of Denisovans than to Neanderthals or modern humans. "This really raises more questions than it answers," Pääbo says.

The team's finding, published online in Nature this week (M. Meyer et al. Nature http://dx.doi.org/10.1038/nature12788;2013), does not necessarily mean that the Sima de los Huesos hominins are more closely related to the Denisovans, a population that lived thousands of kilometres away and hundreds of thousands of years later, than to nearby Neanderthals. This is because the mitochondrial genome tells the history of just an individual's mother, and her mother, and so on.

Nuclear DNA, by contrast, contains material from both parents (and all of their ancestors) and typically provides a more accurate overview of a population's history. But this was not available from the femur.

With that caveat in mind, researchers interested in human evolution are scrambling to explain the surprising link, and everyone seems to have their own ideas.

Pääbo notes that previously published full nuclear genomes of Neanderthals and Denisovans suggest that the two had a common ancestor that lived up to 700,000 years ago. He suggests that the Sima de

$\sum$ los Huesos hominins could

간 represent a founder popula-

tion that once lived all over

Eurasia and gave rise to the two groups. Both may have then carried the mitochon drial sequence seen in the caves. But these mitochondrial lineages go extinct whenever a female does not give birth to a daughter, so the Neanderthals could have simply lost that sequence while it lived on in Denisovan women.

"I've got my own twist on it," says Stringer, who has previously argued that the Sima de los Huesos hominins are indeed early Neanderthals (C. Stringer Evol. Anthropol. 21, 101-107; 2012). He thinks that the newly decoded mitochondrial genome

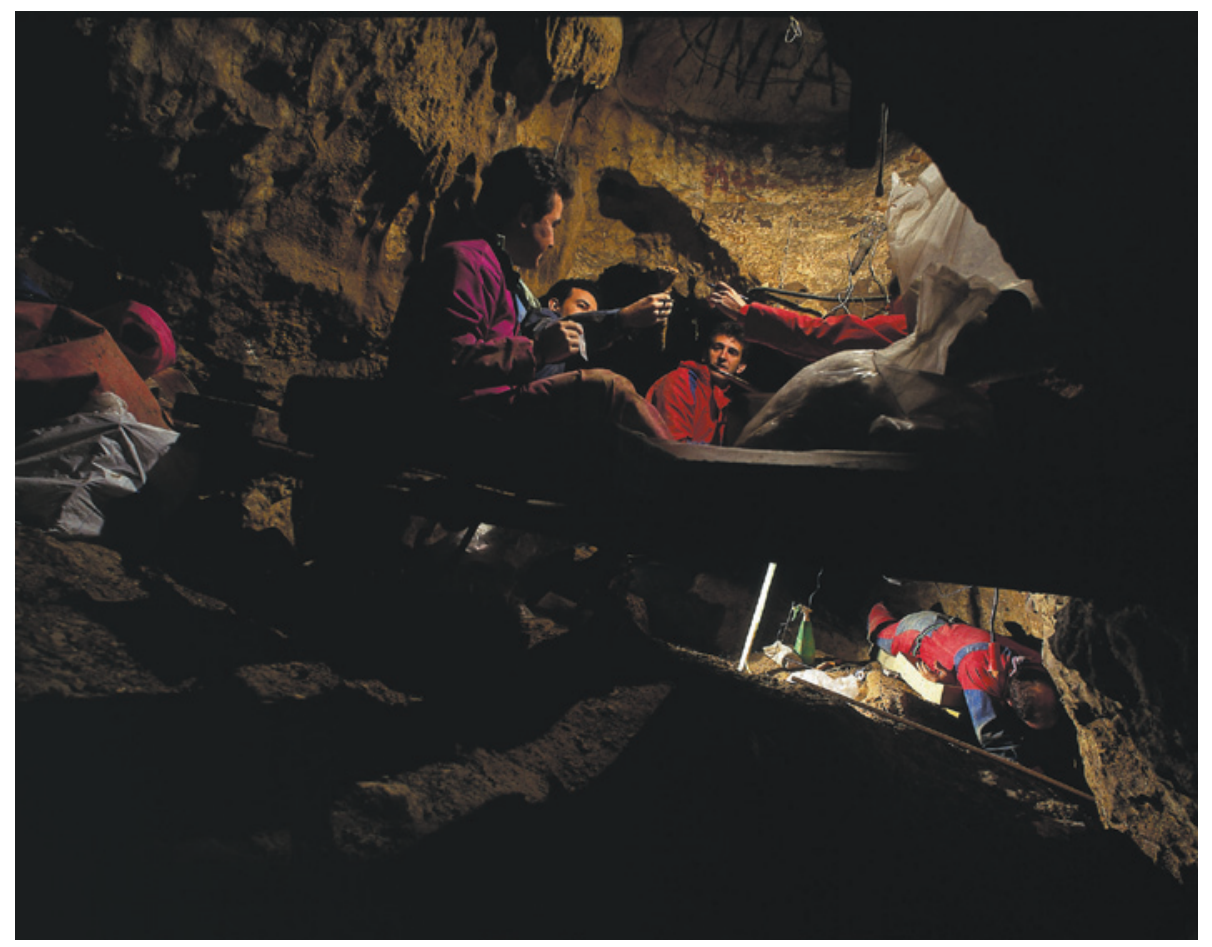

A dig at the Sima de los Huesos cave in Spain, the site of ancient hominin fossils. may have come from another distinct group of hominins. Not far from the caves, researchers have discovered hominin bones from about 800,000 years ago that have been attributed to an archaic hominin called Homo antecessor, thought to be a European descendant of Homo erectus. Stringer proposes that this species interbred with a population that was ancestral to both Denisovans and Sima de los Huesos hominins, introducing the newly decoded mitochondrial lineage to both populations (see 'Family mystery').

This scenario, Stringer says, explains another oddity thrown up by the sequencing of ancient hominin DNA. As part of a widely discussed and soon-to-be-released analysis of high-quality Denisovan and Neanderthal nuclear genomes, Pääbo's team suggests that Denisovans seem to have interbred with a mysterious hominin group (see Nature http://doi.org/p9t; 2013).

The situation will become clearer if Pääbo's team can eke nuclear DNA out of the bones from the Sima de los Huesos hominins, which his team hopes to achieve within a year or so.

Obtaining such sequences will not be simple, because nuclear DNA is present in bone at much lower levels than mitochondrial DNA. And even obtaining the partial mitochondrial genome was not easy: the team had to grind up almost two grams of bone and relied on various technical and computational methods to sequence the contaminated and damaged DNA and to arrange it into a genome. To make sure that they had identified genuine ancient sequences, they analysed only very short DNA strands that contained chemical modifications characteristic of ancient DNA.

Clive Finlayson, an archaeologist at the Gibraltar Museum, calls the latest paper "sobering and refreshing", and says that too many ideas about human evolution have been derived from limited samples and preconceived ideas. "The genetics, to me, don't lie," he adds.

Even Pääbo admits that he was befuddled by his team's latest discovery. "My hope is, of course, eventually we will not bring turmoil but clarity to this world," he says.

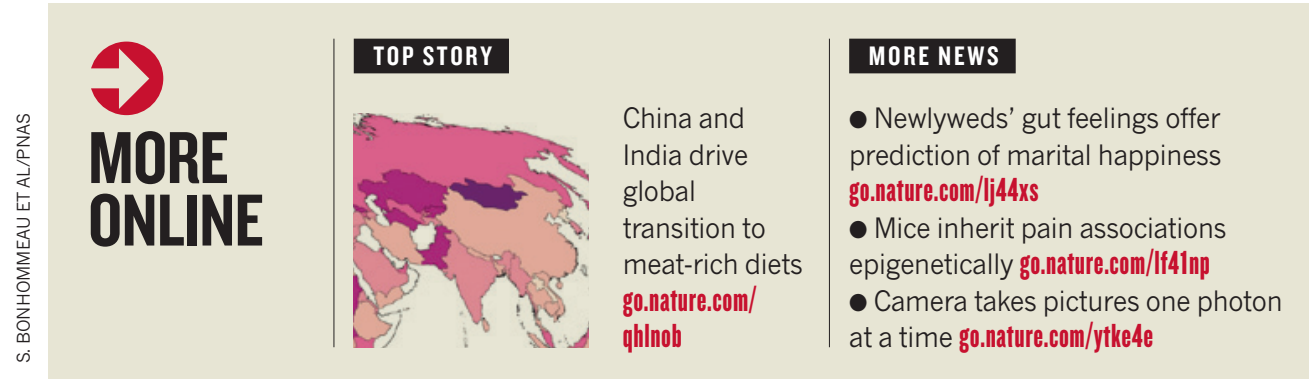

\section{SOUNDBITE OF THE WEEK}

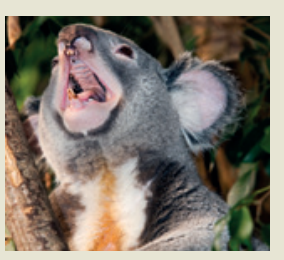

Novel vocal organ explains koalas' deep bellows go.nature.com/ wehsuj 